\title{
A COMPARATIVE STUDY OF THE AMOUNT OF APICALLY EXTRUDED DEBRIS AFTER USING DIFFERENT TYPES OF GLIDE PATH FILES
}

\author{
Mai A. Abdallah ${ }^{I} B D S$, Ashraf M. Zaazou ${ }^{2} P h D$, Nayera A. Mokhless ${ }^{3} P h D$
}

\begin{abstract}
INTRODUCTION: During root canal preparation; irrigants, dentin chips, pulp tissue and microorganisms may be extruded into the periradicular tissues which may cause postoperative pain and complications.

OBJECTIVES: The aim of this study was to compare the amount of apically extruded debris in mesio-buccal canals of 30 extracted human mandibular molars instrumented with One-Shape file after preparing a proper glide path using G-files, ProGlider and K-files.

MATERIALS AND METHOD: This study was conducted on the mesio-buccal roots of 30 human mandibular molars with curvature of 20 to 35 degrees. All specimens were divided into three groups according to the type of instrument used for glide path management. Group (1): manual instrumentation with K-files (\#10, 15), Group (2): G-files: (G1: \#0.12mm, G2: \#0.17mm), and Group (3): ProGlider: single use rotary file. All teeth were instrumented using One-Shape file. Debris extruded apically from the teeth were collected into pre-weighed Eppendorf tubes. Three consecutive weights were obtained for each tube and the mean value was obtained. The weight of extruded debris was calculated as the difference between the pre and post instrumentation weights of the tubes.

RESULTS: The highest amount of debris was found in the k-file group while the lowest amount with ProGlider group with significant differences between them. Moreover, significant difference was found between ProGlider and G -file while there was no significance between G-file and $\mathrm{K}$-file groups.
\end{abstract}

CONCLUSIONS: All techniques showed debris extrusion, although the use of NiTi rotary instruments may be rather beneficial.

KEYWORDS: Apical debris, Glide path, Rotary files.

1- Bachelor of Dentistry, Faculty of Dentistry, Alexandria University, Alexandria, Egypt.

2- Professor of Endodontics, Faculty of Dentistry, Alexandria University, Alexandria, Egypt.

3- Assistant Professor of Endodontics, Faculty of Dentistry, Alexandria University, Alexandria, Egypt.

\section{INTRODUCTION}

One of the key requirements for a successful root canal treatment is thorough cleaning and shaping of the root canal system. Debris extruded during instrumentation consists of necrotic tissues, pulp tissue fragments, microorganisms and irritants which can cause inflammation, pain, delayed healing and flare-ups which may affect the overall success of root canal therapy. The amount of debris varies depending on file size, type and method of instrumentation that should be performed in a manner to minimize the amount of debris extruded into periapical tissues (1).

Negotiation and glide path preparation are the initial phases of chemo-mechanical procedures and can be regarded as crucial steps for assessment of the root canal anatomy and establishment of unimpeded access to the apical part of the canal $(2,3)$. Instruments used for canal negotiation should ideally be of small size and flexible to permit their progression in apical direction with safety and efficiency.

Well shaped canals hold an effective reservoir of irrigant that can penetrate, circulate and clean into the uninstrumentable portions of a root canal system. Glide path management is the single most consequential clinical step that serves to influence the successful fulfillment of the mechanical and biological goals for shaping canals (4).

Glide path is a smooth tunnel from the orifice of the canal to the terminus of the root; its minimal size should be a super loose no. \#10 file. To achieve clean root canal system, it must follow and replicate the original canal path in order to preserve the position on nature's portal of exit locations (5).

A proper glide path will allow rotary nickel-titanium instruments to shape to the apical terminus of the root canal, minimizing the risk of instrument breakage and increasing its life span (6).

Many companies provide either two or three file sequences, in which each file has a traditional, fixed tapered design over the length of its active portion. In general, fixed tapered files require a multi-sequence to promote safety. Mechanical glide path files were recently introduced into the market for creating an initial glide path, reducing procedural chair time and decreasing post-operative pain (7).

The new G-file NiTi rotary instruments were recently introduced by Micro-Mega (Besancon Cedex, France). The system consists of two instruments, G1 ( $\# 0.12 \mathrm{~mm})$ and G2 $(\# 0.17 \mathrm{~mm})$ with $0.3 \mathrm{~mm}$ taper. The single use rotary glide path file named Pro-Glider (DENTSPLY Tulsa Dental Specialties) with variable taper from $2 \%$ to $8 \%$ creates a significantly larger, smoothly tapered pathway than any other multi-file sequence (8) .

The hypothesis of the current study was that the use of different glide path files may influence the amount of apically extruded debris during root canal instrumentation.

\section{MATERIALS AND METHODS}

This study was conducted following the requirements of the Institutional Review Board (IRB) of the faculty of dentistry, Alexandria University regarding research involving human tissues.

Thirty freshly extracted mandibular first molars extracted for periodontal reasons with mesiobuccal canals of moderate curvature (20-35) according to schneider's technique (9) were used.

\section{Preparation of the specimens}

The teeth were thoroughly cleaned from any soft tissue or 
calculus deposition, and then stored in isotonic saline solution until use. Teeth were examined for the presence of any cracks using a magnifying lens. Pre-operative digital radiographs were taken for all teeth in both buccal and proximal directions. For standardization, teeth were decoronated at the level of $17 \mathrm{~mm}$ from the apex, perpendicular to the long axis of the root canal to obtain a relatively standard root canal length at the same time preserving a reservoir for the irrigant. The distal root of each tooth was removed at the level of the cemento- enamel junction with a high speed diamond stone with water spray cooling then it was sealed off using glass ionomer.

Confirmation of apical patency was performed with \#08 or \#10 stainless steel manual K-files until visible at the apical foramen and the working length was determined by substracting $1 \mathrm{~mm}$ from this length. To avoid any bias caused by differences in the initial width, teeth with apical diameter larger than size\#10 were excluded. Two coats of nail varnish were applied to the external surface of all root specimens in order to prevent debris and irrigant extrusion through lateral canals or other discontinuities in the cementum except $1 \mathrm{~mm}$ around the apical foramen.

In this study, the experimental model described by Myers and Montogomery (10) was used. Stoppers were separated from the Eppendorf tubes. For more accurate results, three consecutive weights were obtained for each tube, and the mean value was calculated. A hole was created in each stopper. Each tooth was inserted up to the cemento-enamel junction, and a 27-G needle was placed alongside the stopper to be used as a drainage cannula and to balance the air pressure inside and outside the tubes. Each stopper with the tooth and the needle were attached to its Eppendorf tube, and the tubes were fitted to vials. Vials were labeled with the specific group and specimen number and were covered using aluminum foils to prevent the operator from viewing debris and irrigant extrusion during canal preparation phase. Grouping

All specimens were randomly divided into three groups of ten each, according to the type of instrument used for glide path management.

Group 1: K-type manual files (\#10, \#15,\#20).

Group 2: G1 and G2 of the G-file system.

Group 3: The single ProGlider file.

\section{Glide path preparation}

Group I: the glide - path was established with size \#10,\#15 and \#20 K-type file in a watch winding motion until reaching working length. Group II: the glide path was established with (G1, G2) operated with X-Smart endodontic motor, at $400 \mathrm{rpm}$ with torque set at $1.2 \mathrm{Ncm}$, as recommended by the manufacturer. G1 files were used to reach the working length with a slow movement without pressure and then $\mathrm{G} 2$ files were used in the same way after irrigation. Group III: The ProGlider was used in a rotary motion at $300 \mathrm{rpm}$ and $2 \mathrm{Ncm}$ torque using the same endodontic motor.

During glide path preparation, if any file ceases to advance inward, it was removed and irrigated then step was repeated until reaching the working length. Between change of files, flutes were cleaned, canals were irrigated with distilled water using a 27-gauge side-vented needle, recapitulated with a size \#10 file and the glide path was reconfirmed then re-irrigated with distilled water to liberate loose debris.

$2 \mathrm{ml}$ of irrigating solution was used between each step with total amount of $6 \mathrm{ml}$ used in glide path preparation for each of the tested groups.

\section{Instrumentation}

For all the specimens coronal flaring was performed by using the Endoflare (Micro-Mega Besancon Cedex, France).

All specimens were instrumented using the One-Shape single file (Micro-Mega Besancon Cedex, France) which was introduced into the canals, activated by X-Smart plus electric motor (Dentsply Maillefer, Ballaigues, Switzerland) at $350 \mathrm{rpm}$ and $2.5 \mathrm{Ncm}$ and applied in continuous rotation motion according to the pre-saved program in the motor. OneShape was placed to two thirds of the working length then down to $3 \mathrm{~mm}$ form working length and finally to the full working length. $2 \mathrm{ml}$ of irrigating solution was used between each step. With total amount of $6 \mathrm{ml}$ used for each tested group.

\section{Weighing of debris and irrigant}

After the instrumentation was completed, the stopper, needle, and tooth were separated and removed from the Eppendorf tube, and the debris that adhered to the root surface were collected by washing the root with $1 \mathrm{ml}$ distilled water in the tube. The tubes were stored in an incubator at $70^{\circ} \mathrm{C}$ for five days to evaporate the distilled water before weighing the dry debris.

Weight calculation was performed using the same sensitive balance to obtain the final weight of the tubes including the extruded debris. Three consecutive weights were obtained for each tube. The dry weight of the extruded debris was calculated by subtracting the weight of the empty tube from that of the tube containing debris.

\section{STATISTICAL ANALYSIS}

Data were collected, revised, coded and fed to statistical software SPSS version 20. The given graphs were constructed using Microsoft excel software. All statistical analysis was done using two tailed tests and alpha error of 0.05 .

After data management and validation, amount of extruded debris was calculated for each group using simple mathematical extraction methods. Quantitative data were described using mean, standard deviation, median and minimum and maximum.

The statistical comparison between the three studied groups regarding the difference in weight was done using ANOVA test followed by Post hoc test to determine the level of significance between each two groups.

\section{RESULTS}

The results showed that the highest amount of apical extrusion of debris was found in Group A, using the K-type manual files with a mean of (0.007), followed by Group B with a mean value of (0.006), while the lowest amount of apical debris was found in Group $\mathrm{C}$ with a mean value of (0.003) (Table 1).

On comparing the three studied groups it was found that there was a statistical significant difference between the three studied groups regarding the difference in weight using ANOVA test. Post hoc test was followed to determine the level of significance between each two groups (Table 2, Fig. 1), it was found that there was no significant difference between group A and B (0.298), while there was a significant difference between group A and $\mathrm{C}(0.000127)$ and between group B and C (0.0031). The level of significance was $\mathrm{p}<0.05$. 
Table 1: The mean difference in weight in the three studied groups.

\begin{tabular}{|c|c|c|c|}
\hline & Group A & Group B & Group C \\
\hline $\mathbf{1}$ & 0.004 & 0.010 & 0.003 \\
\hline $\mathbf{2}$ & 0.008 & 0.004 & 0.003 \\
\hline $\mathbf{3}$ & 0.005 & 0.009 & 0.002 \\
\hline $\mathbf{4}$ & 0.009 & 0.009 & 0.001 \\
\hline $\mathbf{5}$ & 0.012 & 0.006 & 0.002 \\
\hline $\mathbf{6}$ & 0.006 & 0.003 & 0.002 \\
\hline $\mathbf{7}$ & 0.005 & 0.003 & 0.004 \\
\hline $\mathbf{8}$ & 0.011 & 0.002 & 0.002 \\
\hline $\mathbf{9}$ & 0.007 & 0.003 & 0.004 \\
\hline $\mathbf{1 0}$ & 0.004 & 0.011 & 0.002 \\
\hline Min & 0.004 & 0.002 & 0.001 \\
\hline Max & 0.012 & 0.011 & 0.004 \\
\hline Mean & 0.007 & 0.006 & 0.003 \\
\hline S.D & 0.003 & 0.003 & 0.001 \\
\hline
\end{tabular}

Table 2: Comparison between the three studied groups regarding the difference in weight.

\begin{tabular}{|c|c|c|c|}
\hline & Group A & Group B & Group C \\
\hline Min & 0.004 & 0.002 & 0.001 \\
\hline Max & 0.012 & 0.011 & 0.004 \\
\hline Mean & 0.007 & 0.006 & 0.003 \\
\hline S.D & 0.003 & 0.003 & 0.001 \\
\hline ANOVA & \multicolumn{3}{|c|}{15.22} \\
P & \multicolumn{3}{|c}{$0.001^{*}$} \\
\hline P1 & 0.298 \\
P2 & \multicolumn{3}{|c}{$0.000127^{*}$} \\
P3 & $0.0031^{*}$ \\
\hline
\end{tabular}

$\mathrm{P} 1$ comparison between group $\mathrm{A}$ and $\mathrm{B}$. $\mathrm{P} 2$ comparison between group $\mathrm{A}$ and $\mathrm{C}$. $\mathrm{P} 3$ comparison between group $\mathrm{B}$ and $\mathrm{C}$.

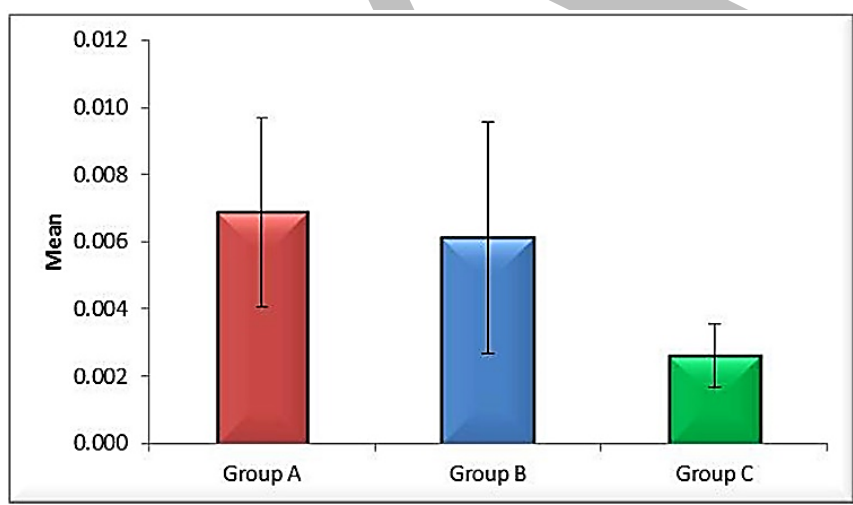

Figure 1: The difference between the three studied groups regarding the weight of extruded debris.

\section{DISCUSSION}

This study evaluated the apical extrusion of debris as a result of root canal preparation after using different glide path files.

The main objectives of root canal preparation are to clean and shape the root canal system, while maintaining the original canal configurations (11). During root canal preparation and irrigation, intra-canal contents are forced to extrude apically as debris containing dentin particles, necrotic pulp tissue remnants, or microorganisms, which might trigger inflammatory reactions in the periapical region $(12,13)$. These objectives have been achieved in a majority of cases by NiTi rotary instruments $(14,15)$. However, in early stages of root canal preparation, these instruments are prone to torsional fractures due to their bindings in the root canal walls $(16,17)$. To reduce this risk, a glide path is required.

The establishment of glide path before root canal preparation might reduce the amount of extruded debris decreasing postoperative pain (18).

To minimize variables, curvature angles were standardized to 25-35 degrees according to Schneider (9). Mesiobuccal canals of mesial roots of mandibular first molars were chosen, as they are often narrow and have accentuated curves that make debridement and shaping more difficult $(19,20)$. This was found in accordance with De-Deus et al (21) and Hegazy et al (22) who preferred using mesial roots of lower molars. Though in the majority of the previous studies single canals were used in assessment of extruded debris as, Myers and Montgomery (10), because of the ease in set up in the collector apparatus and cleaning and shaping procedures are easier and more predictable.

In our work, teeth with apical diameter larger than size \#10 were excluded. Tinaz et al (23) stated that variation in apical foramen size between the specimens would actually affect the amount of apically extruded debris and irrigant. However, Al-Omari and Dummer (24) found no significant correlation between apical diameter and amount of extruded debris.

In this study, instrumentation was confined to $1 \mathrm{~mm}$ short of the apical foramen has previously shown to contribute to significantly less debris extrusion $(10,25)$. Whereas, Martin and Cunningham (26) demonstrated greater debris extrusion when canals were instrumented at a length where the file was observed to just protrude through the apical foramen versus 1 $\mathrm{mm}$ short of the apical foramen.

The amount of irrigating solution was kept constant in all groups in the present study to decrease variables. Distilled water was used for irrigation according to Burklein et al (27) to avoid any possible weight increase due to crystallization of sodium hypochlorite.

By using this standardized tooth model in the current study, the amounts of collected extruded materials were mostly a result of instrumentation differences, and not the tooth morphology or inter operative errors (28).

The One-Shape NiTi instrument was used for all the three groups after using three different glide path system files, to see their effect on apical debris extrusion. It was preferred to use a single file as explained by Kucukilmaz et al (29) who stated that the single file OneShape extruded less debris than the full sequence ProTaper and this was also in agreement with Tanalp et al (30) who mentioned that increasing number of instruments may increase the amount of apical debris extrusion. Moreover, the rotary motion may improve the coronal augering of debris by acting like a screw conveyer pulling debris into the flutes of the file and directing it toward the coronal aspect of the canal $(25,27,30)$. However, Lu Y et al $(31)$, found that the use of reciprocating single file systems resulted in less apical extrusion than full sequence rotary instruments. On the contrary, Topcuoglu et al (18) found that irrespective of type of motion used whether reciprocating or rotary, no 
significant difference was found if glide path was created.

In the present study, all groups showed extrusion of irrigant and debris, however, it was found that creating glide-path using rotary files produced lower amounts of debris extrusion than using manual stainless steel K-type files. This was in accordance with $\mathrm{Ha}$ et al (32) who found the rotary glide path systems produced less apical extrusion than manual instrumentation. The results can be explained by differences in instrument geometric designs and movement kinematics between systems (33).

The filing motion of K-file creates a greater pressure apically which may tend to push irrigant and debris through the foramen, with less space available to push it coronally. This was in agreement with Tanalp et al (30) and Alomari and Dummer (24), who found that linear filing action packs the debris more tightly in the apical $1 \mathrm{~mm}$.

On the other hand, the better results obtained using glide-path rotary instruments could be attributed to the early removal of debris from the root canal and maintenance of the working length and patency, allowing for an increased flow of irrigating solutions to the apical root canal. Instrumentation with rotary NiTi systems remains more centered in the root canal, this results in less transport of materials than hand filing with stainless steel files (34).

In the present study, there was no significant difference between the G-file group and $\mathrm{K}$-file group, although better results were obtained with the G-file group. This could be attributed to the narrow diameter (\#12 and\#17) with a slight .03 taper of the files. Also along the length of the instrument, the G- file having cutting edges on three different radii, acting with a snake like behaviour, creating a large and efficient area for upward debris removal. The angular offset of the cutting edges also creates a different pitch along the length of the blade, avoiding any screwing or engaging effects on the canal wall. The nonworking tip is asymmetric, which helps the instrument move forward. Another reason is that G-files are electro polished which improves their mechanical properties by releasing internal stresses which develop during machining increasing their flexibility and increasing the efficiency in apical progression of the files while aiding in debris removal (35).

According to our study, the Pro-Glider group showed the least significant amount of debris extrusion. These better results obtained when compared to the G-file might be due to its design features having progressive taper from $2 \%$ to $8 \%$ along its length. This was in accordance with Baranwal et al (36) who found that ProGlider removed the coronal dentin restriction, followed and expanded original anatomy, improving shaping results, reducing chair time and decreasing postoperative pain which was also in accordance with Ha et al (32) who explained that ProGlider resulted in major debris removal from the coronal third of the canal which has a similar effect as that of crown down preparation concept using an instrument with a larger taper. The file has improved flexibility and high resistance to cyclic fatigue as manufactured from M-Wire NiTi with a square cross section (37). This was confirmed by Baranwal et al (36) who found that ProGlider having Mwire technology showed superior physical and mechanical properties than conventional NiTi wire for manufacturing rotary instrument and respects the anatomy of root canals better than manual instrumentation resulting in less risk of transportation, ledges or apical zips.These previous design features, with the simplicity of a single file, could provide a powerful instrument to predictably follow and enlarge the natural glide path in a controlled, smooth, inward cutting action with less potential to screw effect.

It must be emphasized that the results of this study cannot be directly extrapolated to the clinical situation. Under clinical conditions, periapical tissues and bone serve as natural barriers against the apical extrusion of debris and irrigants. Some investigators have suggested simulating the resistance of periapical tissues using floral foam $(38,39)$. However, this approach may encourage absorption of irrigant and debris which may affect the results. Also, chemo mechanical instrumentation of vital and necrotic teeth plays an influential role in apical extrusion. In vital teeth, the pulp stump present serves as a barrier preventing extrusion of debris while in necrotic teeth no such resistance can be found (40).

\section{CONCLUSIONS}

Rotary glide path files showed less amount of apical extruded debris than hand files which might result in less postoperative pain. Less amount of debris was obtained with the ProGlider glide path file.

\section{ACKNOWLEDGEMENT}

I would like to thank my father and my professors for their continuous support during conduction of this study.

\section{CONFLICT OF INTEREST}

The authors declare that they have no conflicts of interest.

\section{REFERENCES}

1. Reddy SA, Hicks ML. Apical extrusion of debris using two hand and two rotary instrumentation techniques. J Endod. 1998; 24: 180-3.

2. Peters OA, Peters CI. Cleaning and shaping of the root canal system. In: Hargreaves KM, Cohen S (eds). Cohen's pathways of the pulp. $10^{\text {th }}$ ed. St Louis, MO: Mosby, 2010. pp 283-348.

3. Siqueira JF Jr, Lopes HP, Chemomechanical preparation. In: Siqueira JF Jr (ed). Treatment of endodontic infectious. London: Quintessence Publishing, 2011. pp 236-84.

4. Cassim I, van der Vyver PJ. The importance of glide path preparation in endodontics: a consideration of instruments and literature. SADJ. 2013; 68: 324-7.

5. West JD. The endodontic glide path:" Secret to rotary safety". Dent Today 2010; 29:86-93.

6. Patino PV, Biedma BM, Liebana CR, Cantatore G, Bahillo JG. The influence of a manual glide path on the separation rate of NiTi rotary instruments. J Endod. 2005; 31: 114-6.

7. Pasqualini D, Mollo L, Scotti N,Cantatore G, Castellucci A, Migliaretti G,et al. Postoperative pain after manual and mechanical glide path: a randomized clinical trial. J Endod 2012; 38:32-6.

8. Ruddle CJ, Machtou P, West JD. Endodontic Canal Preparation: Innovations in Glide path management and shaping canals. Dent Today 2014; 33:118.

9. Schneider SW. A comparison of canal preparations in straight and curved root canals. Oral Surg Oral Med Oral Pathol. 1971; 32: 271-5.

10. Myers GL, Montgomery S. A comparison of weights of debris extruded apically by conventional filing and canal master techniques. J Endod. 1991; 17: 275-9.

11. Ruddle CJ. Cleaning and shaping the root canal system. In: Cohen S, Burn RC (eds). Pathways of the pulp. $8^{\text {th }}$ ed. St. 
Louis, MO: Mosby Elsevier, 2002. 231-92.

12. Seltzer S, Naidorf IJ. Flare-ups in endodontics: I. Etiological factors. J Endod. 1985; 11: 472-8.

13. Seltzer S, Naidorf IJ. Flare-ups in endodontics: II. Therapeutic measures. J Endod. 1985; 11: 559-67.

14. Yun HH, Kim SK. A comparison of the shaping abilities of 4 nickel-titanium rotary instruments in simulated root canals. Oral Surg Oral Med Oral Pathol Oral Radiol Endod. 2003; 95: 228-33.

15. Sonntag D, Guntermann A, Kim SK, Stachniss V. Root canal shaping with manual stainless steel files and rotary Ni-Ti files performed by students. Int Endod J. 2003; 36: 246-55.

16. Sattapan B, Nervo GJ, Palamara JE, Messer HH. Defects in rotary nickel-titanium files after clinical use. J Endod. 2000; 26: 161-5.

17. Cheung GSP. Instrument fracture: mechanisms, removal of fragments, and clinical outcomes. Endod Topics. 2007; 16: $1-26$.

18. Topcuoglu HS, Duzgun S, Akpek F, Topçuoğlu G, Aktı A. Influence of a glide path on apical extrusion of debris during canal preparation using single-file systems in curved canals. Int Endod J. 2016; 49: 599-603.

19. Paque F, Musch U, Hulsmann M. Comparison of root canal preparation using Race and Protaper rotary Ni-Ti instruments. Int Endod J. 2005; 38: 8-16.

20. Celik D, Tasdemir T, Er K. Comparative study of six rotary nickel-titanium systems and hand instrumentation for root canal preparation in severely curved root canals of extracted teeth. J Endod. 2013; 39: 278-82.

21. De-Deus G, Brandao MC, Barino B, Di Giorgi K, Fidel RA, Luna AS. Assessment of apically extruded produced by the single file ProTaper F2 technique under reciprocating movement. Oral Surg Oral Med Oral Pathol Oral Radiol Endod. 2010; 110: 390-4.

22. Hegazy A, Moussa MS, Sherif R. Comparative study on the effect of using pathfiles system prior to using two rotary nickel titanium systems on the amount of apically extruded debris. M.Sc. Thesis. Faculty of Dentistry, University of Alexandria. 2013.

23. Tinaz AC, Alacam T, Uzun O, Maden M, Kayoglu G. The effect of disruption of apical constriction on periapical extrusion. J Endod. 2005; 31: 533-5.

24. Al-Omari MAO, Dummer PMH. Canal blockage and debris extrusion with eight preparation techniques. J Endod. 1995; 21: $154-8$.

25. Beeson TJ, Hartwell GR, Thornton JD, Gunsolley JC. Comparison of debris extruded apically in straight canals: Conventional filing versus Profile 0.04 Taper Series 29. J Endod. 1998; 24: 18-22.

26. Martin H, Cunningham WT. The effect of endosonic and hand: Manipulation on the amount of root canal material extruded. Oral Surg Oral Med Oral Pathol. 1982; 53: 611-3.

27. Burklein S, Schafer E. Apically extruded debris with reciprocating single-file and full-sequence rotary instrumentation systems. J Endod. 2012; 38: 850-2.

28. Bidar M, Rastegar AF, Ghaziani P, Namazikhah MS. Evaluation of apically extruded debris in conventional and rotary instrumentation techniques. J Calif Dent Assoc. 2004; 32: 665-71.

29. Kucukyilmaz E, Savas S, Saygili G, Uysal B. Assessment of apically extruded debris and irrigant produced by different nickel-titanium instrument systems. Braz Oral Res. 2015; 29: 1-6.
30. Tanalp J, Kaptan F, Sert S, Kayahan B, Bayirl G. Quantitative evaluation of the amount of apically extruded debris using three rotary instrumentation systems. Oral Surg Oral Med Oral Pathol Oral Radiol Endod. 2006; 101: 2529.

31. Lu Y, Chen M, Qiao F, Wu L. Comparison of apical and coronal extrusions using reciprocating and rotary instrumentation systems. BMC Oral Health. 2015; 7: 15-92.

32. Ha JH, Kim SK, Kwak SW, El Abed R, Bae YC, Kim HC. Debris extrusion by glide-path establishing endodontic instruments with different geometries. J Dent Sci. 2016; 11: 136-40.

33. Arslan NG, Doganay E, Alsancak M, Capar ID, Karatas E, Gunduz HA. Comparison of apically extruded debris after root canal instrumentation using reciproc( $\left({ }^{\circledR}\right)$ instruments with various kinematics. Int Endod J. 2016; 49: 307-10.

34. Tasdemir T, Er K, Celik D,Aydemir H. An in vitro comparaison of apically extruded debris using three rotary nickel titanium instruments. J Dent Sci. 2010; 5: 121-5.

35. D'amario M, Baldi M, Petricca R, De angelis F, Elabed R, D'arcangelo C. Evaluation of a new nickel titanium system to create the glide path in root canal preparation of curved canals. J Endod. 2013; 39:1581-4.

36. Baranwal HC, Baranwal AK. Proglider files-next step in glide path preparation. APRD. 2016; 2:60-2.

37. Johnson E, Lloyd A, Kuttler S, Namerow K. Comparison between a novel nickel-titanium alloy and 508 nitinol on the cyclic fatigue life of ProFile 25/.04 rotary instruments. J Endod. 2008; 34: 1406-9.

38. Hachmeister DR, Schindler WG, Walker WA, Thomas DD. The sealing ability and retention characteristics of mineral trioxide aggregate in a model of apexification. J Endod. 2002; 28: 386-90.

39. Altundasar E, Nagas E, Uyanik O, Serper A. Debris and irrigants extrusion potential of two rotary systems and irrigation needles. Oral Surg Oral Med Oral Pathol Oral Radiol Endod. 2011; 112: 31-5.

40. Kustarci A, Akdemir N, Siso SH, Altunbas D. Apical extrusion of intracanal debris using two engine driven and step back instrumentation techniques: an in-vitro study. Eur J Dent. 2008; 2: 233-9. 